\title{
BMJ Open LIVES for families psychological first aid training programme to address COVID-19 psychological distress: a mixed methods acceptability and feasibility protocol
}

To cite: Kimber M, Harms S, Soreni N, et al. LIVES for families psychological first aid training programme to address COVID-19 psychological distress: a mixed methods acceptability and feasibility protocol. BMJ Open 2021;11:e049995. doi:10.1136/ bmjopen-2021-049995

- Prepublication history and additional supplemental material for this paper are available online. To view these files, please visit the journal online (http://dx.doi.org/10.1136/ bmjopen-2021-049995).

Received 08 February 2021 Revised 25 March 2021 Accepted 20 April 2021

Check for updates

(C) Author(s) (or their employer(s)) 2021. Re-use permitted under CC BY-NC. No commercial re-use. See rights and permissions. Published by BMJ.

For numbered affiliations see end of article.

Correspondence to

Dr Melissa Kimber;

kimberms@mcmaster.ca

\section{ABSTRACT}

Introduction Best practice approaches for addressing COVID-19-related psychological distress among young people ( $<25$ years) and their families remain unclear. Psychological first aid (PFA) is promoted by public health authorities to provide psychological support in the context of extreme events; however, there is limited evidence for its effectiveness. As a prerequisite to conducting a randomised controlled trial to examine programme effectiveness, this project is evaluating the acceptability and feasibility of implementing and evaluating a PFA training programme ('LIVES for Families') for mental health $(\mathrm{MH})$ practitioners to improve their ability to recognise and respond to COVID-19-related psychological distress among their clients.

Methods and analysis We are using a triangulation mixed methods research design; complementary strands of quantitative and qualitative data are being collected in parallel and will be merged at the interpretation phase of the project. The quantitative strand uses a repeated measures design; a consecutive sample of $\mathrm{MH}$ practitioners $(\mathrm{n}=80)$ providing $\mathrm{MH}$ support to young people or their families are being recruited to participate in the LIVES for Families PFA training programme and complete quantitative measures at baseline (pretraining), 2-week and 6-month follow-up time points. The qualitative strand uses fundamental description and semistructured interviews with a subset of practitioners $(n=30)$, as well as managers of $\mathrm{MH}$ agencies $(\mathrm{n}=20)$. A mixed methods joint display and associated narrative will generate a comprehensive understanding regarding acceptability and feasibility.

Ethics and dissemination The Hamilton Integrated Research Ethics Board approved the study (project number: 11295). Results will be shared broadly with the policy and practice community through publications, presentations and public webinars. As a brief, evidenceinformed intervention, the LIVES for Families PFA training programme is suitable in its mode of delivery across care settings. The outcomes of this study could have international implications for mitigating the $\mathrm{MH}$ impacts of viral pandemics.
Strengths and limitations of this study

Although our projected sample size meets methodological guidelines for acceptability and feasibility studies, it is small and estimates of statistical significance must be interpreted with caution.

- Our sample will include mental health clinicians from diverse sectors of mental health services, which will enhance the relevance and applicability of findings in different regions.

- This study uses a mixed methods design; the combination of qualitative and quantitative data strengthens the credibility and applicability of acceptability and feasibility findings.

- A limitation of this work is the absence of data collection from youth and adults with psychological distress related to COVID-19.

- A strength of this work is a strong collaborative relationship with community-based mental health agencies and a local Youth and Family Engagement Co-Development Team, whose members have lived experience with mental health challenges and who are consulting on this research.

\section{INTRODUCTION}

There is increasing evidence about the widespread negative psychological effects of COVID-19. ${ }^{1-3}$ These include direct effects of the virus on neurobiological vulnerability to mental health $(\mathrm{MH})$ conditions, ${ }^{4-6}$ as well as the indirect effects of financial, occupational and relational stressors related to restricted social mobility, extended periods of social isolation, as well as reduced availability of education, health and childcare services via public measures to contain the spread of COVID-19. ${ }^{7-10}$ A recent position paper on this issue highlighted additional risks for psychological distress during the pandemic, including exposure to substance misuse, 
gambling and disruption of social networks. ${ }^{1}$ This statement is supported by increasing epidemiological studies using self-reported and caregiver-reported measures of $\mathrm{MH}$ functioning, which note rise in depressive and anxiety symptoms, as well as sleep disturbances, and general psychological distress in children and youth. ${ }^{11-16}$ Equally concerning is the high level of caregiver-related stress documented among parents (and grandparents) of children and youth during the pandemic, ${ }^{17-25}$ and elevated reports of intimate partner violence and couple conflict. ${ }^{26-32}$ All of these factors highlight the urgent need to evaluate interventions that target COVID-19-related psychological distress in caregivers, children and youth.

With permission from the World Health Organization (WHO), we adapted the LIVES psychological first aid (PFA) framework (detailed below) to develop a novel PFA training programme for front-line MH practitioners to address COVID-19-related psychological distress among children and youth (up to the age of 25; referred to as 'young people') and their family members. Called 'LIVES for Families', this training programme includes several pedagogical elements, including three virtual training sessions, the application of the PFA intervention in clinical practice and the completion of practice logs to support practitioners' use of the intervention during their clinical encounters. This paper outlines the methodological protocol for determining the acceptability and feasibility of conducting a future randomised controlled trial (RCT) to evaluate the effectiveness of the 'LIVES for Families' PFA training programme to improve psychological well-being among young people and their families via improvements to $\mathrm{MH}$ practitioners' preparedness and self-efficacy for addressing pandemic-related psychological distress in their practice encounters.

\section{PFA during viral pandemics and extreme events}

PFA is defined by the WHO as 'a humane, supportive response to someone who is suffering and may need support' in the context of an extreme event, disaster or large-scale crisis (p 3). ${ }^{33}$ Originally developed for the purposes of training 'lay persons' to provide widespread support during environmental disasters, PFA training has since expanded to paraprofessionals and licensed practitioners, as well as a broader range of extreme events. Based on a decade of reviews, ${ }^{34-37}$ PFA has been used to support young people ${ }^{37-41}$ and adults ${ }^{37} 4243$ following weather disasters, ${ }^{38} 424445$ civil war and politically based violence, ${ }^{394044}$ and more recently in acute responses to viral epidemics, such as Ebola. ${ }^{374146}$ In a few small nonrandomised studies, PFA training significantly improved PFA provider perceptions of their self-efficacy in addressing adversity among crisis survivors; ${ }^{45}{ }^{47-49}$ this was recently confirmed in an RCT that evaluated the effectiveness of a 1-day PFA training on provider knowledge for appropriate responses and skills following an Ebola outbreak in Sierra Leone. ${ }^{50}$

Despite these promising findings, there are significant methodological weaknesses in the existing evidence for
PFA. Available studies are at high risk for bias and there have been few replications across contexts. ${ }^{34-37} 51-53$ PFA programmes have focused on training 'lay persons' and medical professionals, as well as reducing psychological distress and sequelae (eg, post-traumatic stress disorder) in these populations. PFA interventions delivered by MH practitioners have been less studied, as has the longitudinal impact of PFA interventions on a broader set of $\mathrm{MH}$ outcomes. Finally, few PFA studies have simultaneously considered the impacts of PFA on the MH outcomes of PFA providers and their clients. This is despite research which indicates that vulnerability to psychological distress may be amplified among practitioners who are simultaneously supporting crisis-affected individuals, while attempting to cope with their own crisis-based responses. ${ }^{54-59}$ Furthermore, few studies have considered the influence of PFA educational and implementation outcomes (eg, provider readiness, preparedness, adherence) on the $\mathrm{MH}$ impacts of PFA interventions. This is concerning given evidence from the field of implementation science, which indicates that therapist readiness and adherence to intervention protocols can influence intervention impacts. ${ }^{60-63}$

\section{LIVES for Families PFA programme}

Our evidence review suggested that PFA models generally focus on: (A) providing connection and calm to those emotionally distressed by the crisis; (B) orienting individuals to the potential impacts of the crisis on community and individual well-being (ie, psychoeducation); (C) improving self-efficacy related to managing one's emotional and practical needs; (D) recognising the possibility for safety vulnerabilities (eg, risk for pandemicrelated harm) and developing safety plans; and (E) facilitating access to more intensive $\mathrm{MH}$ assessment and intervention, where indicated. ${ }^{34-36}$ 64-66 The delivery of PFA builds on the use of empathy and active listening skills and is distinct from psychological counselling, debriefing and psychotherapy. ${ }^{33}$ PFA's focus is on providing nonintrusive, emotional and practical support to individuals to assist them with managing distress that is related to their specific experience of the large-scale crisis or event.

Our team developed the LIVES for Families PFA training programme (hereafter referred to as LIVES for Families) by adapting the WHO LIVES framework, which was developed to support front-line practitioners to provide PFA to women who have experienced sexual violence or intimate partner violence ${ }^{6768}$ The framework has been broadly disseminated by the WHO across low and middle-income countries and is used as a model for PFA. Given its emphasis on meeting the emotional and practical needs of those in crisis, we received permission from the WHO to: (A) adapt the core elements of the LIVES framework to align with delivering PFA for COVID-19-related psychological stressors among young people and families; and (B) evaluate LIVES for Families during the COVID-19 context.

LIVES for Families follows an interactive and practicebased curriculum over the course of one 'core' and two 
'practice' sessions; sessions are focused on improving the practitioner's knowledge, skills and self-efficacy related to supporting young people and their caregivers to recognise and address their own (and if relevant, their child's) COVID-19 psychological stressors. Informed by the cumulative stress model ${ }^{6-71}$ and self-efficacy theory, ${ }^{72-75}$ the core ( 3 hours) and practice ( 1.5 hours each) training sessions include up to 20 trainees, are delivered virtually by two trained facilitators and occur 2 weeks apart. Training sessions are standardised via the use of a structured facilitators guide and include brief didactic instruction, experiential role-play, ${ }^{76}$ case-based learning ${ }^{77}$ and associated learning tools (eg, knowledge summaries, clinician scripts). Blended learning strategies focus on learner engagement through active learning, ${ }^{78} 79$ deliberate practice, ${ }^{80}$ test-enhanced learning ${ }^{81}$ and experiential learning to support knowledge acquisition, skill development and self-efficacy in model elements. The two follow-up 'practice' sessions were added based on evidence that 1-day training sessions result in inconsistent practice change and PFA delivery. ${ }^{82-88}$ To further support the integration of newly learnt concepts into their clinical practice, enrolled practitioners are asked to track their use of the PFA intervention in their clinical encounters using a practice log. Core and practice training sessions cover the following content areas: (1) specific COVID-19-related psychological stressors, (2) the use of PFA in pandemics, (3) the PFA framework, and (4) case application. Table 1 provides an overview of the intended learning outcomes, pedagogical strategies, as well as supporting resources used in each of the LIVES for Families training sessions.

The overall aim of the present project is to determine the acceptability and feasibility of LIVES for Families, as a prerequisite to conducting an RCT to evaluate the effectiveness of LIVES for Families in reducing COVID-19 psychological stressors among young people and their caregivers. Table 2 provides the detailed objectives of our acceptability and feasibility research programme.

Table 1 LIVES for Families PFA training programme

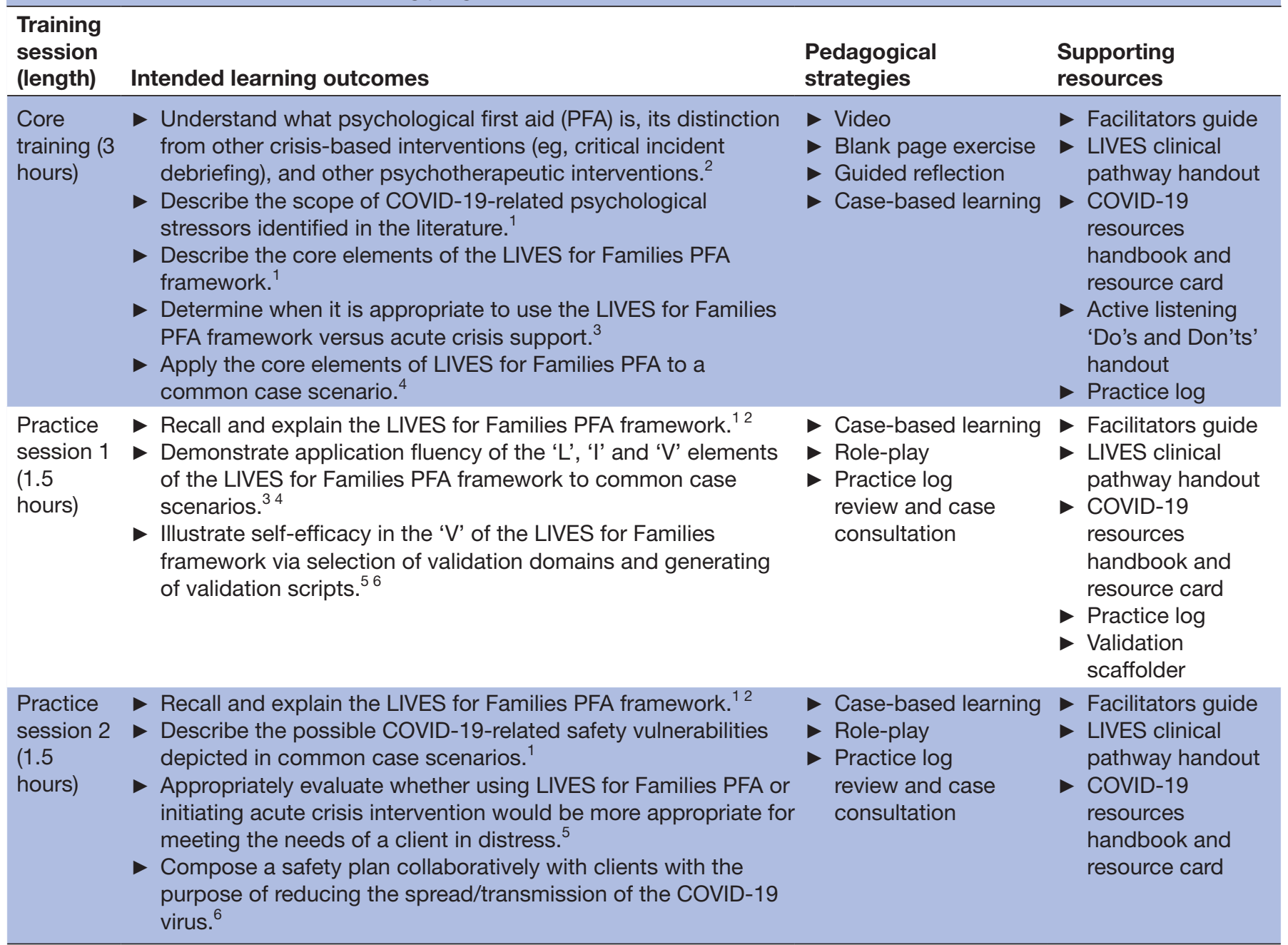

Each of the LIVES for Families PFA intended learning outcomes has been mapped to one of the six levels of Bloom's taxonomy of learning, ${ }^{133} 134$ which provides a hierarchical framework for understanding the cognitive processes needed to foster optimal learning related to a complex construct or phenomenon. The assigned level of taxonomy for each intended learning outcome is given by one or more of the following notations: $1=$ =remembering; $2=$ understanding; $3=$ =pplying; $4=$ =analysing; $5=$ =valuating; $6=$ creating. 


\begin{tabular}{l} 
Table 2 Acceptability and feasibility research objectives \\
\hline Objectives \\
Primary \\
Determine the number of MH practitioners who \\
meet study eligibility criteria and who enrol in the \\
LIVES for Families PFA training programme (overall \\
and per week of recruitment). \\
Assess the proportion of enrolled MH practitioners \\
who complete the LIVES for Families PFA training \\
programme as a measure of acceptability of \\
the programme; with completion consisting of \\
participation and completion of all three training \\
sessions. \\
Determine the feasibility of collecting training \\
programme outcome (ie, secondary objective) \\
data among eligible and enrolled MH practitioners \\
at baseline, 2 -week and 6-month follow-up time \\
points. \\
Explore the acceptability of the LIVES for \\
Families PFA training programme and evaluation \\
procedures in a subsample of eligible and \\
participating MH practitioners and their managers. \\
Determine whether completion of the LIVES for \\
Families PFA training programme among enrolled \\
MH practitioners leads to significant improvements \\
in their self-reported preparedness and self- \\
efficacy related to recognising and responding to \\
COVID-19-related stressors among their clients. \\
Determine whether completion of the LIVES for \\
Families PFA training programme among enrolled \\
MH practitioners leads to significant changes in \\
self-reported measures of burn-out and secondary \\
traumatic stress. \\
Secondary
\end{tabular}

$\mathrm{MH}$, mental health; PFA, psychological first aid.

\section{METHODS \\ Design}

We are using a triangulation mixed methods research design (see figure 1); quantitative and qualitative strands of data collection are occurring in parallel, being given equal priority, and will be merged at the analytical and interpretation phases of the project. ${ }^{89}$ The strands of data collection are being connected via purposefully sampling a subgroup of enrolled practitioners to complete both strands. The quantitative strand will follow a nonexperimental, repeated measures design. ${ }^{90} \mathrm{~A}$ consecutive, convenience sample of MH practitioners $(n=80)$ are being recruited to participate in LIVES for Families training and complete quantitative assessments. This quantitative strand will provide acceptability and feasibility metrics related to enrolment, retention, attrition and data completeness. The qualitative strand will follow the principles of qualitative description ${ }^{91} 92$ to complete individual, semistructured qualitative interviews with: (A) $\mathrm{MH}$ practitioners who completed all LIVES for Families training sessions $(n=30)$; and (B) managers of local MH agencies $(n=20)$. The qualitative data will provide contextual information about our quantitative metrics from the perspective of multiple stakeholders, including participating practitioners and managers. ${ }^{93} 94$

\section{Setting}

The primary study location is Hamilton, Canada, a diverse urban centre in the south-central region of Ontario with a population of more than 500000 residents, $11.5 \%$ of whom are $0-19$ years of age. ${ }^{95}$

\section{Quantitative research strand}

Design, sampling and recruitment

The quantitative strand is following a non-experimental, repeated measures design. ${ }^{90}$ Practitioner-level outcomes of primary interest for an effectiveness study will be assessed at multiple time points to: (A) determine the acceptability and feasibility of outcome data collection; and (B) generate preliminary estimates of variability in our practitioner outcomes, which can inform sample size estimations for an RCT. A sample size of approximately 40 participants is generally sufficient for acceptability and feasibility studies. ${ }^{96-98}$ Since retention may be challenging due to the pandemic, we plan to recruit a consecutive convenience sample of $80 \mathrm{MH}$ practitioners (18 years of age or older) who provide psychosocial or psychotherapeutic support to young people and/or their caregivers. Sampling and recruitment of practitioners from Hamilton area agencies began in August 2020 and ended in January 2021.

Eligible practitioners: (A) are currently employed within a publicly funded MH service agency, school board, primary care clinic, child welfare organisation, tertiary MH programme, or a private counselling or psychotherapy practice; (B) have been providing psychotherapeutic or psychosocial support to young people (ie, $<25$ years of age) or their caregivers for at least 1 day/week, over the previous year; and $(\mathrm{C})$ intend on continuing to provide support to young people or their caregivers throughout the study period (ie, for a period of 6 months or longer following study enrolment). Managers who are eligible to participate in the qualitative research strand (detailed below) are those who provide oversight or supervision of practitioners in a Hamilton-based MH agency. Exclusion criteria for practitioners and managers include the inability to speak or read English.

Recruitment of practitioners occurred through a three-pronged approach. First, study information letters were distributed to potentially interested participants via Hamilton's lead public child and youth MH agency, Lynwood Charlton Centre (LCC). LCC provides direct MH service to young people and their caregivers, and collaborates with 19 community-based service partners, including 15 other children's MH service agencies, four school boards, two family health team and two child welfare agencies. Recruitment materials were circulated to potentially eligible practitioners via email by the leadership of LCC and each LCC partner. Recruitment materials provide information on study eligibility, consent, enrolment and data collection procedures. This process was 


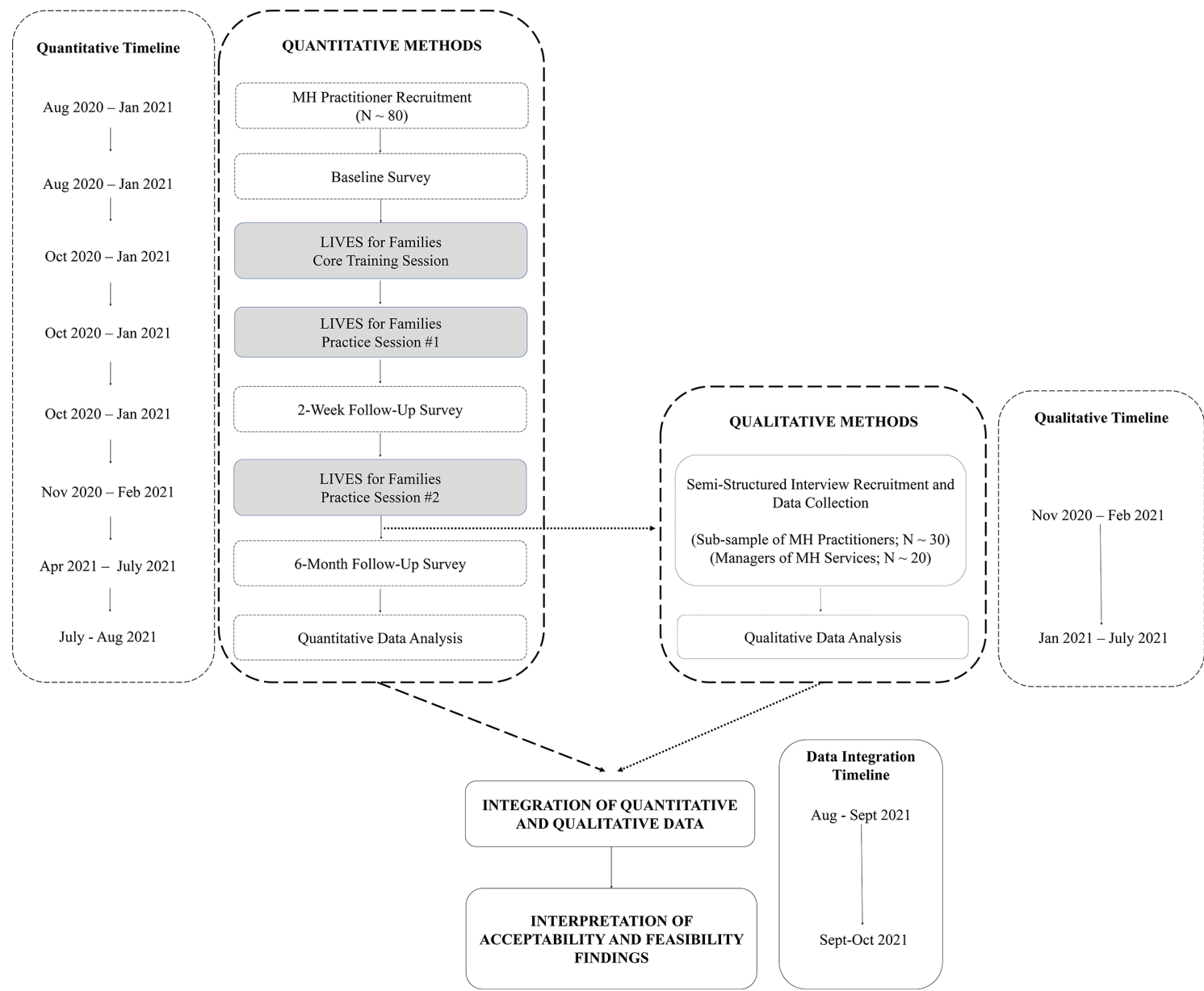

Figure 1 Trianguation mixed methods research design (QUAN+QUAL) and associated timeline for each strand of data collection. Quantitative and qualitative data collection occurs in parallel and then merged after being separately analysed. The strands of data collection are purposefully integrated via a subsample of practitioners who are purposefully recruited to complete qualitative and quantitative data collection procedures. ( $\mathrm{MH}$, mental health).

supplemented with an email request to the managers of non-LCC partner organisations to distribute study materials to their staff, as well as posting project recruitment materials on social media platforms. Snowball sampling methods were also used with each 'source' participant. Each practitioner will receive a $\$ 120.00$ honorarium in the form of an e-gift card after 6-month follow-up assessment; e-gift cards are a token of appreciation for the completion of all three quantitative research assessments.

\section{Intervention}

Enrolled practitioners will complete the LIVES for Families training virtually, which is cofacilitated by two members of the research team (MK, SH and/or NS). Practice sessions will begin 2 weeks following the core training and will be 2 weeks apart.

\section{Data collection}

\section{Primary objectives}

Quantitative data (see table 2) are being collected by the project's research coordinator (RC); these include the number of participants who: (A) inquire about study participation; (B) are eligible/ineligible after screening; and $(\mathrm{C})$ enrol. The $\mathrm{RC}$ is also tracking the number of:
(D) contacts needed to complete consent and arrange all research assessments and LIVES for Families training sessions; (E) dropouts following consent; (F) contacts who could not be reached for follow-up; (G) training sessions completed; $(\mathrm{H})$ the quantitative research assessments completed across time points; and (I) those who are approached, agree, complete and withdraw from the qualitative data collection strand.

\section{Secondary objectives}

Data are being collected via practitioners' self-completion of assessments administered by email at three time points: 1 week before their 'core' training session (time 1; baseline); immediately following the first practice session (time 2; 2-week follow-up); and 6 months following their baseline research assessment (time 3; 6-month follow-up). Participants can opt to complete measures by phone (see table 2).

\section{Measures related to secondary objectives}

In addition to sociodemographic characteristics (sex at birth, gender identification, age, professional discipline, years of practice, socioeconomic status, etc), we will assess the administration of measures that capture 
possible outcomes, mediators, moderators and covariates to be included in any subsequent effectiveness trial to determine the acceptability and feasibility of our quantitative assessment approach. A detailed description for each of these measures and their timing is provided in online supplemental appendix 1 . Briefly, at each of the three time points, practitioners will self-report on their: (A) readiness to change their practice related to learning about and deliver PFA (adapted version of the Brief Individual Readiness to Change Scale ${ }^{99}$ ); (B) preparedness to recognise and respond to the COVID-19 psychological stressors experienced by their clients (adapted version of the Preparedness Subscale of the Physician Readiness to Manage Intimate Partner Violence Survey ${ }^{100}{ }^{101}$ ); (C) perceived self-efficacy to deliver PFA (adapted version of the Personal Self-Efficacy Subscale of the Self-Efficacy and Outcome Expectancy Scale for Job-Related Applications measure ${ }^{102}$ ); and (D) their perceptions of their own stress and well-being related to COVID-19 (adapted version of the CoRonavIruS health Impact Survey version $\left.1.0^{103}\right)$. The 6-month research assessment will also ask practitioners to self-report their level of burn-out and secondary traumatic stress using adapted versions of the Maslach Burnout Inventory ${ }^{104}$ and the Secondary Traumatic Stress Scale, ${ }^{105}$ respectively.

\section{Data analysis}

Since this project is focused on acceptability and feasibility, an a priori sample size estimation is not required. Our quantitative primary objectives will be addressed via generating estimates of dispersion and central tendency (ie, proportions, means, SDs, etc). A priori thresholds of acceptability and feasibility for our primary objectives (1), (2) and (3) have been established as follows: (1) acceptable levels of eligibility and enrolment will be (i) a $90 \%$ or greater screening eligibility rate for practitioners or managers who self-refer to the study; and (ii) a recruitment rate of, on average, 10 practitioners per week and the achievement of our sample aims within 8 weeks; (2) the acceptable proportion of enrolled practitioners who complete all of the LIVES for Families training sessions will be $75 \%$ or greater; and (3) the feasibility of collecting quantitative outcome data among enrolled practitioners will be indicated by: (i) less than $20 \%$ missing data at the practitioner and group level for each time point, and (ii) our RC is able to generate estimates of effect and variability (with robust SEs) for the measures related to the secondary objectives of the current study. Quantitative secondary objectives will be addressed via generating bivariate correlations and regression coefficients for our selected measures. Measures will be examined for multicollinearity, ${ }^{106}$ as well as any needed transformation due to unfavourable skewness and kurtosis. ${ }^{107}$

\section{Qualitative research strand}

Design, sampling and recruitment

Qualitative description will be used to generate a comprehensive summary of the perceived experience and impact of the LIVES for Families training programme, as well as perceived burden related to programme completion and research activities. ${ }^{92} 108$ Data from qualitative interviews will corroborate, expand, and extend what's learnt about acceptability and feasibility from the quantitative strand, as well as provide information about potential barriers and facilitators related to PFA training programme implementation and evaluation from the perspective of practitioners and managers.

According to methodological guidelines for the triangulation design and fundamental description, sample size expectations should be made in consideration of the function of the qualitative strand of data collection. ${ }^{109} 110$ We are using purposive, criterion-based and maximum variation sampling strategies to recruit a subsample of practitioners ( $\mathrm{n} 30$ ) who complete all LIVES for Families training sessions to contribute qualitative research data. We are also recruiting a sample of managers (n 20) responsible for supporting $\mathrm{MH}$ practitioners on the front lines of the pandemic. Criterion sampling is a form of purposeful sampling which selects participants on the basis of predetermined criteria (eg, completion of all training sessions) that are deemed critical to addressing the study's research objectives. ${ }^{111}$ Maximum variation sampling is a form of group-based purposeful sampling capable of identifying both diverse and shared perspectives across a range of participants. ${ }^{112}$ We are operationalising maximum variation sampling via inviting practitioners and managers who are working in diverse practice contexts in the Hamilton region, as well as practitioners who represent diverse levels and types of training to participate in this strand of data collection. Qualitative interview data are being collected in parallel to the quantitative strand of data collection. Manager sampling and recruitment follows the same process outlined for practitioners above and began following completion of the first LIVES for Families training cohort. Given the homogenous nature of the qualitative sample of participants, we anticipate that these expected sample sizes will achieve data sufficiency.

\section{Data collection}

Practitioners and managers are being asked to participate in a one-on-one, semistructured interview with a member of the project team. Rubin and Rubin ${ }^{113}$ describe the use of qualitative interviews as a strategy to examine an issue/phenomenon in a natural manner and identify similar and contradictory perceptions. A semistructured interview guide consisting of five to seven key, openended questions (see table 3) is guiding data collection and is informed by primary objective 4 . In keeping with the traditions of inductive qualitative inquiry, interview probes are being adapted throughout data collection to explore emerging patterns in the data. ${ }^{114}$ Practitioner and manager interviews are scheduled between 45 and $60 \mathrm{~min}$ via Zoom at a time that is convenient for participants. Each individual interview will be audio recorded and transcribed verbatim. Qualitative interview participants 
Table 3 Core qualitative interview questions for practitioners and managers

\section{Questions for practitioners}

Question Question

No

1 What is your perspective on the potential value of psychological first aid during the COVID-19 pandemic?

How would you describe your experience with the
LIVES for Families PFA training?
How would you describe your experience of living
through the pandemic while having to provide
psychosocial/psychotherapeutic support to your
clients?

$4 \quad$ What has it been like for you to incorporate
the 'LIVES for Families' psychological first aid
intervention in your clinical practice?

$6 \quad$ From your perspective as a practitioner, what are some important aspects of diversity that come to mind for you when we think about providing psychological first aid in a pandemic?

Questions for managers

$1 \quad$ What is your perspective on the value of psychological first aid during the COVID-19 pandemic?

2 As a manager, how would you describe your comfort level (or lack thereof) in supporting your staff to participate in a psychological first aid training during a pandemic?

\begin{tabular}{|c|c|}
\hline 3 & $\begin{array}{l}\text { What kind of supports would need to be in place to } \\
\text { enable your team's participation in a psychological } \\
\text { first aid training opportunity? }\end{array}$ \\
\hline 4 & $\begin{array}{l}\text { What, from your perspective, are the factors that } \\
\text { can create challenges for your practitioners and/or } \\
\text { agency to participate? }\end{array}$ \\
\hline 5 & $\begin{array}{l}\text { During a pandemic, practitioners are simultaneously } \\
\text { coping with public health restrictions, while also } \\
\text { supporting their clients with pandemic-related } \\
\text { stressors. Please describe for us how this point } \\
\text { resonates with you, if at all? }\end{array}$ \\
\hline 6 & $\begin{array}{l}\text { From your perspective as a manager, what are some } \\
\text { important aspects of diversity that come to mind for } \\
\text { you when we think about providing psychological } \\
\text { first aid in a pandemic? }\end{array}$ \\
\hline
\end{tabular}

PFA, psychological first aid.

are being provided a $\$ 40.00$ honorarium in the form of an e-gift card at the completion of the interview. Field notes completed by the interviewer are documenting observations, patterns or dialectical positions which may be relevant to our analysis.

\section{Data analysis}

Transcripts of interviews with practitioners and managers, as well as associated field notes, will be imported into
NVivo for data management and will be analysed using: (1) directed (deductive) content analysis; (2) reflective (inductive) thematic analysis; and (3) summative content analysis. ${ }^{115} 116$ Directed content analysis will include the RC's establishment of a codebook with a set of a priori codes corresponding to the acceptability and feasibility objectives (eg, enrolment, compliance, measurement burden) and indexing their application to the interview transcripts. Reflective thematic analysis ${ }^{117}$ and analytical memoing ${ }^{118}$ allow for the codebook to expand via the identification of new concepts, constructs or factors (and their relationships). Summative content analysis and constant comparison will allow for quantifying the number and salience of finalised codes within and across interviews from our data sources. The codebook will contain the following key elements: code name, full definition, instructions for the application of the code and a brief excerpt of data relevant to the code. ${ }^{119}$ The initial iteration of the codebook will be generated by the RC. Research team members with expertise in qualitative research methods, health profession education, psychotherapeutic interventions and intervention science (MK, $\mathrm{SH}, \mathrm{AA}$ ) will also independently code a sample of the interview data; consistency of code application will be assessed via consensus-based discussion. The initial codebook will be revised as needed and applied in its finalised format to all interview data.

\section{Methodological rigour and integration of quantitative and qualitative strands of data}

Informed by mixed methods guidelines, ${ }^{120}$ the use of investigator and data source triangulation, analytical memos, decision audit trailing, repeated quantitative assessments, as well as psychometrically validated measures of core concepts for our secondary outcomes will ensure the credibility (internal validity), dependability (reliability) and transferability (external validity) of our quantitative, qualitative and mixed methods analyses and interpretations. ${ }^{904121-123}$ Integration of qualitative and quantitative findings will occur during the interpretation phase of our project. Quantitative acceptability and feasibility metrics generated for our primary objectives will be mapped to the counts of perceived barriers and facilitators to acceptability and feasibility (and associated excerpts of qualitative data) via a mixed methods joint display. ${ }^{121} \mathrm{In}$ addition, a modified stem-and-leaf plot will cross-tabulate scores on measures for our secondary objectives (eg, practitioner preparedness, confidence, secondary traumatic stress, burn-out, etc) with qualitative excerpts describing the perceived value and potential impact of the LIVES for Families training programme. ${ }^{115116121}$

\section{Patient and public involvement}

Cofacilitated by one of the team's coinvestigators (MI), our acceptability and feasibility project benefits from the experience of young people and caregivers who participate on the LCC's Youth and Family Engagement Co-Development Team (YFE-CDT), which is a team of 
individuals who have lived experience with receiving $\mathrm{MH}$ support from practitioners in the Hamilton community. Plans for up to six meetings of approximately 2 hours in duration with members of the YFE-CDT have been developed as part of the project's engagement strategy; two meetings have occurred to date. Engagement thus far has included soliciting YFE-CDT members' input regarding the development and clinical implementation of LIVES for Families (eg, what practitioners should be trained and why; what COVID-19-related psychological stressors should be integrated as appropriate 'training cases' to support the programme's relevance). The YFE-CDT will be consulted on the most appropriate methods for communicating the project findings. Where appropriate, YFE-CDT members will have the opportunity to collaborate in knowledge dissemination and knowledge translation activities. Our approach is supported by evidence noting limited research that includes the voices of individuals who have been impacted by the COVID-19 pandemic and its associated public health restrictions. ${ }^{124-128}$

\section{ETHICS AND DISSEMINATION}

This study was approved by the Hamilton Integrated Research Ethics Board (project number: 11295). Informed consent is being obtained from all potential participants; on consent, each participant is being assigned a randomly generated study identification (ID) code; quantitative study data will be tracked via participant study IDs and all identifying information will be removed from the qualitative interview transcripts.

Several key deliverables and knowledge dissemination strategies will accelerate the translation of our research findings. We will publish our findings in open-access journals according to mixed methods guidelines ${ }^{120}$ and results will be shared broadly with the policy, practice and academic communities via conference presentations and public webinars. The strategic use of digital and social media will be used to disseminate project updates and results, as well as generate brief, professionally produced infographics and summaries for dissemination.

\section{DISCUSSION}

The LIVES for Families PFA training programme is an innovative, brief and evidence-informed training programme for $\mathrm{MH}$ practitioners to address psychological distress experienced by their clients and which is related to the COVID-19 pandemic. We have proposed a mixed methods study to determine the acceptability and feasibility of the training programme as a prerequisite to examining effectiveness of the programme in an RCT. This complex psychosocial intervention has important attributes that make it applicable to the COVID-19 pandemic; it can be flexibly delivered within and across practitioners, it addresses several different outcomes (eg, secondary traumatic stress, burn-out, anxiety and depressive symptoms, etc) across multiple stakeholders (eg, practitioners, patients) and can be integrated into existing organisational service models across various contexts during the pandemic. For example, in Canada, $\mathrm{MH}$ practitioners provide support in diverse settings (eg, hospitals, clinics, schools, homes, etc). Before implementing an RCT of a complex intervention, it is important to determine its acceptability and feasibility among practitioners, and whether an effectiveness trial can and should be done, and if so, the necessary design and implementation processes. ${ }^{129-132}$

The present study has several strengths. First, as a mixed methods protocol, the combination of quantitative and qualitative data will generate a more comprehensive understanding of acceptability and feasibility from the perspective of multiple stakeholders. Second, the triangulation of data types from practitioners with diverse training backgrounds who are providing $\mathrm{MH}$ services across an array of settings during the pandemic will enhance the credibility, transferability and trustworthiness of our findings. Another important strength of this project is a strong, collaborative partnership between the research team, Hamilton's lead agency for child and youth MH services, LCC, and their respective YFE-CDT.

There are two principal limitations of this project: (1) the lack of opportunity to collect data regarding the perceived value and impact of the PFA training programme from the perspective of young people and their caregivers; and (2) the quantitative strand of data collection follows a single-arm repeated measures design, which precludes the possibility of making any claims regarding the ability of the PFA training programme to lead to changes in our secondary outcomes of interest (ie, increased preparedness and self-efficacy, reduced burn-out and secondary traumatic stress, etc).

The LIVES for Families training programme was developed with the overall objective of providing a brief and scalable intervention for front-line $\mathrm{MH}$ practitioners to deliver practical and emotional support to young people and their family members who are experiencing psychological distress due to COVID-19. Informed by models of cumulative stress and self-efficacy, the programme has also been developed to address the potential for burn-out and secondary traumatic stress in the $\mathrm{MH}$ workforce. ${ }^{69-71}$ These models provide a constructive framework for considering how the broader impacts of the LIVES for Families PFA training programme can be quantified, explained and leveraged within and across service contexts and potentially, countries.

\section{Author affiliations}

${ }^{1}$ Department of Psychiatry and Behavioural Neurosciences, McMaster University, Hamilton, Ontario, Canada

${ }^{2}$ Offord Centre for Child Studies, Hamilton, Ontario, Canada

${ }^{3}$ Department of Health Research Methods, Evidence, and Impact, McMaster

University, Hamilton, Ontario, Canada

${ }^{4}$ Lynwood Charlton Centre, Hamilton, Ontario, Canada

${ }^{5}$ Department of Pediatrics, McMaster University, Hamilton, Ontario, Canada

Twitter Melissa Kimber @mel_kimber and Anita Acai @anita_acai 
Acknowledgements We are grateful to all participants for their clinical and research contributions during the COVID-19 pandemic; each of these individuals is providing an important research and clinical service via their participation. We also thank the Hamilton Integrated Research Ethics Board for their rapid review of the project's ethics application and any amendments. We acknowledge the support of the WHO via their permission to adapt the LIVES framework to address the project's goals. HLM acknowledges her support from the Chedoke Health Chair in Child Psychiatry at McMaster University. The team is grateful to Dr Alexander Drossos for his feedback on the original grant submission; the team is also grateful to Rosemary Georges, who is the research coordinator on the acceptability and feasibility study.

Contributors MK, SH, NS, MI, AA, ELL, RS, DLS and HLM made substantial contributions to the conception and design of the LIVES for Families training and research project. MK prepared the protocol and drafted all sections of the manuscript. All authors read, edited and approved the manuscript for submission.

Funding The LIVES for Families PFA training and research project is supported by the Canadian Institutes of Health Research (CIHR; funding reference number: VR5-172663)

Disclaimer The views expressed in this publication are those of the authors and do not necessarily reflect the views of the $\mathrm{CIHR}$ or the WHO. The CIHR and the WHO had no role in study design, data collection and analysis, decision to publish or preparation of the manuscript.

Competing interests None declared.

Patient consent for publication Not required

Provenance and peer review Not commissioned; peer reviewed for ethical and funding approval prior to submission.

Supplemental material This content has been supplied by the author(s). It has not been vetted by BMJ Publishing Group Limited (BMJ) and may not have been peer-reviewed. Any opinions or recommendations discussed are solely those of the author(s) and are not endorsed by BMJ. BMJ disclaims all liability and responsibility arising from any reliance placed on the content. Where the content includes any translated material, BMJ does not warrant the accuracy and reliability of the translations (including but not limited to local regulations, clinical guidelines, terminology, drug names and drug dosages), and is not responsible for any error and/or omissions arising from translation and adaptation or otherwise.

Open access This is an open access article distributed in accordance with the Creative Commons Attribution Non Commercial (CC BY-NC 4.0) license, which permits others to distribute, remix, adapt, build upon this work non-commercially, and license their derivative works on different terms, provided the original work is properly cited, appropriate credit is given, any changes made indicated, and the use is non-commercial. See: http://creativecommons.org/licenses/by-nc/4.0/.

\section{ORCID iDs}

Melissa Kimber http://orcid.org/0000-0002-1255-8947

Anita Acai http://orcid.org/0000-0002-9901-2946

David L Streiner http://orcid.org/0000-0003-0610-6271

\section{REFERENCES}

1 Holmes EA, O'Connor RC, Perry VH, et al. Multidisciplinary research priorities for the COVID-19 pandemic: a call for action for mental health science. Lancet Psychiatry 2020;7:547-60.

2 Salari N, Hosseinian-Far A, Jalali R, et al. Prevalence of stress, anxiety, depression among the general population during the COVID-19 pandemic: a systematic review and meta-analysis. Global Health 2020;16:57.

3 Nearchou F, Flinn C, Niland R, et al. Exploring the impact of COVID-19 on mental health outcomes in children and adolescents: a systematic review. Int J Environ Res Public Health 2020;17

4 Vindegaard N, Benros ME. COVID-19 pandemic and mental health consequences: systematic review of the current evidence. Brain Behav Immun 2020;89:531-42.

5 Lindan CE, Mankad K, Ram D. Neuroimaging manifestations in children with SARS-CoV-2 infection: a multinational, multicentre collaborative study. Lancet Child Adolesc Health 2021;5:167-77.

6 Mazza MG, De Lorenzo R, Conte C, et al. Anxiety and depression in COVID-19 survivors: role of inflammatory and clinical predictors. Brain Behav Immun 2020;89:594-600.

7 Brooks SK, Webster RK, Smith LE, et al. The psychological impact of quarantine and how to reduce it: rapid review of the evidence. Lancet 2020;395:912-20.
8 Racine N, Cooke JE, Eirich R, et al. Child and adolescent mental illness during COVID-19: a rapid review. Psychiatry Res 2020;292:113307.

9 Singh S, Roy D, Sinha K, et al. Impact of COVID-19 and lockdown on mental health of children and adolescents: a narrative review with recommendations. Psychiatry Res 2020;293:113429.

10 Loades ME, Chatburn E, Higson-Sweeney N, et al. Rapid systematic review: the impact of social isolation and loneliness on the mental health of children and adolescents in the context of COVID-19. J Am Acad Child Adolesc Psychiatry 2020;59:1218-39.

11 Yeasmin S, Banik R, Hossain S, et al. Impact of COVID-19 pandemic on the mental health of children in Bangladesh: a crosssectional study. Child Youth Serv Rev 2020;117:105277.

12 Zhou S-J, Zhang L-G, Wang L-L, et al. Prevalence and sociodemographic correlates of psychological health problems in Chinese adolescents during the outbreak of COVID-19. Eur Child Adolesc Psychiatry 2020;29:749-58.

13 Xie X, Xue Q, Zhou Y, et al. Mental health status among children in home confinement during the coronavirus disease 2019 outbreak in Hubei Province, China. JAMA Pediatr 2020;174:898.

14 Young Minds Y. Coronavirus: impact on young people with mental health needs. London, UK: Young Minds, 2020.

15 Phillipou A, Meyer D, Neill E, et al. Eating and exercise behaviors in eating disorders and the general population during the COVID -19 pandemic in Australia: Initial results from the COLLATE project. Int $J$ Eat Disord 2020;53:1158-65.

16 Van Rheenen TE, Meyer D, Neill E, et al. Mental health status of individuals with a mood-disorder during the COVID-19 pandemic in Australia: initial results from the COLLATE project. $J$ Affect Disord 2020;275:69-77.

17 Marchetti D, Fontanesi L, Mazza C, et al. Parenting-related exhaustion during the Italian COVID-19 lockdown. J Pediatr Psychol 2020;45:1114-23.

18 Prikhidko A, Long $\mathrm{H}$, Wheaton MG. The effect of concerns about COVID-19 on anxiety, stress, parental burnout, and emotion regulation: the role of susceptibility to digital emotion contagion. Front Public Health 2020;8:567250.

19 Hiraoka D, Tomoda A. Relationship between parenting stress and school closures due to the COVID-19 pandemic. Psychiatry Clin Neurosci 2020;74:497-8

20 Brown SM, Doom JR, Lechuga-Peña S, et al. Stress and parenting during the global COVID-19 pandemic. Child Abuse Negl 2020;110:104699.

21 Ren J, Li X, Chen S, et al. The influence of factors such as parenting stress and social support on the state anxiety in parents of special needs children during the COVID-19 epidemic. Front Psychol 2020;11:565393.

22 Ren J, Li X, Chen S, et al. The influence of factors such as parenting stress and social support on the state anxiety in parents of special needs children during the COVID-19 epidemic. Front Psychol 2020;11:565393.

23 Lee SJ, Ward KP, Chang OD, et al. Parenting activities and the transition to home-based education during the COVID-19 pandemic. Child Youth Serv Rev 2021;122:105585.

24 Fancourt D, Steptoe A, Bu F. Trajectories of anxiety and depressive symptoms during enforced isolation due to COVID-19 in England: a longitudinal observational study. Lancet Psychiatry 2021;8:141-9.

25 Cacioppo M, Bouvier S, Bailly R, et al. Emerging health challenges for children with physical disabilities and their parents during the COVID-19 pandemic: the echo French survey. Ann Phys Rehabil Med 2020:101429.

26 Lee J. Mental health effects of school closures during COVID-19. Lancet Child Adolesc Health 2020;4:421.

27 Bradbury-Jones C, Isham L. The pandemic paradox: the consequences of COVID-19 on domestic violence. J Clin Nurs 2020;29:2047-9.

28 Allen-Ebrahimian B. China's domestic violence epidemic. AXIOS, 2020. Available: https://www.axios.com/china-domesticviolencecoronavirus-quarantine-7b00c3ba-35bc-4d16-afddb76ecfb28882.html [Accessed 7 Mar 2020].

29 Duncan E. NSW domestic violence support groups warn coronavirus isloation is prompting surge in demand for services, 2020. Available: https://www.abc.net.au/news/2020-03-27/ coronavirus-domestic-family-violence-covid-19-surge/12096988 [Accessed 27 Mar 2020].

30 Reuters News Agency. As domestic abuse rises in Lockdown, France to fund hotel rooms, 2020. Available: https://www.aljazeera. com/news/2020/03/domestic-abuse-rises-lockdown-france-fundhotel-rooms-200331074110199.html

31 Brianda ME, Roskam I, Gross JJ. Treating parental burnout: impact of two treatment modalities on burnout symptoms, emotions, hair 
cortisol, and parental neglect and violence. Psychother Psychosom 2020:1-3.

32 Mikolajczak M, Brianda ME, Avalosse $\mathrm{H}$, et al. Consequences of parental burnout: its specific effect on child neglect and violence. Child Abuse Negl 2018;80:134-45.

33 World Health Organization. Psychological first aid: guide for field workers. Geneva, Switzerland: World Health Organization, 2011.

34 Fox JH, Burkle FM, Bass J, et al. The effectiveness of psychological first aid as a disaster intervention tool: research analysis of peerreviewed literature from 1990-2010. Disaster Med Public Health Prep 2012;6:247-52.

35 Dieltjens T, Moonens I, Van Praet K, et al. A systematic literature search on psychological first aid: lack of evidence to develop guidelines. PLoS One 2014;9:e114714.

36 Shultz JM, Forbes D. Psychological first aid: rapid proliferation and the search for evidence. Disaster Health 2014;2:3-12.

37 Cénat JM, Mukunzi JN, Noorishad P-G, et al. A systematic review of mental health programs among populations affected by the Ebola virus disease. J Psychosom Res 2020;131:109966.

38 Cain DS, Plummer CA, Fisher RM, et al. Weathering the storm: persistent effects and psychological first aid with children displaced by Hurricane Katrina. J Child Adolesc Trauma 2010;3:330-43.

39 de Freitas Girardi J, Miconi D, Lyke C, et al. Creative expression workshops as psychological first aid (Pfa) for asylum-seeking children: an exploratory study in temporary shelters in Montreal. Clin Child Psychol Psychiatry 2020;25:483-93.

40 Brymer MJ, Taylor M, Escudero P. Psychological first aid for schools: field operations guide. National Child Traumatic Stress Network, 2012

41 Kamara S, Walder A, Duncan J, et al. Mental health care during the Ebola virus disease outbreak in Sierra Leone. Bull World Health Organ 2017;95:842-7.

42 Hechanova RM, Ramos PAP, Waelde L. Group-based mindfulnessinformed psychological first aid after Typhoon Haiyan. Disaster Prev Manag 2015;24:610-8.

43 Hechanova MR, Manaois JO, Masuda H. Evaluation of an organization-based psychological first aid intervention. Disaster Prev Manag 2019;28:401-11.

44 Schafer A, Snider L, Sammour R. A reflective learning report about the implementation and impacts of psychological first aid (Pfa) in Gaza. Disaster Health 2016:3:1-10.

45 Allen B, Brymer MJ, Steinberg AM, et al. Perceptions of psychological first aid among providers responding to Hurricanes Gustav and IKe. J Trauma Stress 2010;23:509-13.

46 CBM WHO, Vision W, et al. Psychological first aid for Ebola virus disease outbreak. Geneva, Switzerland: World Health Organization, 2014.

47 Lee J-S, You S, Choi Y-K, et al. A preliminary evaluation of the training effects of a didactic and simulation-based psychological first aid program in students and school counselors in South Korea. PLoS One 2017:12:e0181271.

48 Lalani N, Drolet J. Effectiveness of psychological first aid training for social work students, practitioners and human service professionals in Alberta, Canada. J Pract Teach Learn 2018;17.

49 Choi YJ. Psychological first-aid experiences of disaster health care workers: a qualitative analysis. Disaster Med Public Health Prep 2019:1-4.

50 Sijbrandij M, Horn R, Esliker R, et al. The effect of psychological first aid training on knowledge and understanding about psychosocial support principles: a cluster-randomized controlled trial. Int $J$ Environ Res Public Health 2020;17 doi:10.3390/ijerph17020484

51 WHO, United Nations High Commission for Refugees. mhGAP humanitarian intervention guide (mhGAP-HIG): clinical management of mental, neurological, and substance use conditions in humanitarian emergencies. Geneva, Switzerland: WHO, 2015.

52 Sphere Association. The sphere Handbook: humanitarian charter and minimum standards in humanitarian response. 4th edn. Geneva, Switzerland: Sphere Association, 2018

53 Inter-Agency Standing Committee (IASC). Mental health and psychosocial support in humanitarian emergencies: what should humanitarian health actors know? Geneva, Switzerland: IASC, 2010.

54 Orrù G, Marzetti F, Conversano $C$, et al. Secondary traumatic stress and burnout in healthcare workers during COVID-19 outbreak. Int $J$ Environ Res Public Health 2021;18 doi:10.3390/ijerph18010337

55 Boscarino JA, Figley CR, Adams RE. Compassion fatigue following the September 11 terrorist attacks: a study of secondary trauma among New York City social workers. Int J Emerg Ment Health 2004;6:57-66.

56 Culver LM, McKinney BL, Paradise LV. Mental health professionals' experiences of vicarious traumatization in post-hurricane Katrina New Orleans. J Loss Trauma 2011;16:33-42.
57 Aafjes-van Doorn K, Békés V, Prout TA, et al. Psychotherapists' vicarious traumatization during the COVID-19 pandemic. Psychol Trauma 2020;12:S148-50.

58 Quitangon G, St Cyr K, Nelson C, et al. Vicarious trauma in mental health professionals following the $9 / 11$ terrorist attacks. J Mental Dis Treat 2016;2.

59 McCormack HM, Maclntyre TE, O'Shea D. The prevalence and cause(s) of burnout among applied psychologists: A systematic review. Front Psychol 1897;2018:9.

60 Benito KG, Machan J, Freeman JB. Therapist behavior during exposure tasks predicts habituation and clinical outcome in three randomized controlled trails for pediatric OCD, 2020: 1-16.

61 Mauricio AM, Rudo-Stern J, Dishion TJ, et al. Provider readiness and adaptations of competency drivers during scale-up of the family Check-Up. J Prim Prev 2019;40:51-68.

62 Orte Socias C, Sanchez-Prieto L, Pascual Barrio B. The association between trainer expertise and changes in adolescent symptomatology in an evidence-dased family prevention programme. J Evid Based Soc Work 2021;2019:1-16.

63 Frank HE, Becker-Haimes EM, Kendall PC. Therapist training in evidence-based interventions for mental health: a systematic review of training approaches and outcomes. Clin Psychol Sci Pract 2020;27.

64 Shah K, Bedi S, Onyeaka H. The role of psychological first aid to support public mental health in the COVID-19 pandemic. Cureus2020;12:e8821.

65 Shah K, Kamrai D, Mekala H, et al. Focus on mental health during the coronavirus (COVID-19) pandemic: applying learnings from the past outbreaks. Cureus 2020;12:e7405.

66 Birkhead GS, Vermeulen K. Sustainability of psychological first aid training for the disaster response workforce. Am J Public Health 2018;108:S381-2.

67 WHO. Health care for women subjected to intimate partner violence or sexual violence: a clinical Handbook. Geneva, Switzerland: WHO, 2014.

68 WHO. Responding to intimate partner violence and sexual violence against women: who clinical and policy guidelines. Geneva, Switzerland: WHO, 2013

69 Figley CR. Compassion fatigue as secondary traumatic stress disorder: An overview. In: Figley CR, ed. Compassion fatigue: coping with secondary traumatic stress disorder in those who treat the traumatized. New York, NY: Brunner-Routledge, 1995: 1-20.

70 Figley CR, Ludick M. Secondary traumatization and compassion fatigue. In: Gold SN, ed. APA Handbook of trauma psychology: foundations in knowledge. New York, NY: American Psychological Association, 2017.

71 Flannelly KJ, Roberts RSB, Weaver AJ. Correlates of compassion fatigue and burnout in chaplains and other clergy who responded to the September 11th attacks in New York City. J Pastoral Care Counsel 2005;59:213-24

72 Turner KMT, Nicholson JM, Sanders MR. The role of practitioner self-efficacy, training, program and workplace factors on the implementation of an evidence-based parenting intervention in primary care. J Prim Prev 2011;32:95-112.

73 Bandura A. Self-Efficacy: toward a unifying theory of behavioral change. Psychol Rev 1977;84:191-215.

74 Schiele BE, Weist MD, Youngstrom EA, et al. Counseling selfefficacy, quality of services and knowledge of evidence-based practices in school mental health. Professional Counselor 2014:4:467-80.

75 David P, Schiff M. Self-Efficacy as a mediator in bottom-up dissemination of a research-supported intervention for young, traumatized children and their families. J Evid Inf Soc Work 2017;14:53-69.

76 Fominykh M, Leong P, Cartwright B. Role-playing and experientia learning in a professional counseling distance course. $J$ Int Learn Res 2018;29:169-88.

77 McLean SF. Case-Based learning and its application in medical and health-care fields: a review of worldwide literature. J Med Educ Curric Dev 2016:3:3

78 Austin JP, Carney PA, Thayer EK, et al. Use of active learning and sequencing in a Weekly continuing medical education/ graduate medical education conference. J Contin Educ Health Prof 2019;39:136-43.

79 Chen KS, Monrouxe L, YH L. Academic outcomes of flipped classroom learning: a meta-analysis. Med Educ 2018.

80 Anders Ericsson K, Ericsson KA. Deliberate practice and acquisition of expert performance: a general overview. Acad Emerg Med 2008;15:988-94.

81 Larsen DP, Butler AC, Roediger HL. Test-enhanced learning in medical education. Med Educ 2008;42:959-66. 
82 Horn R, O'May F, Esliker R, et al. The myth of the 1-day training: the effectiveness of psychosocial support capacity-building during the Ebola outbreak in West Africa. Glob Ment Health 2019;6:e5.

83 Bodn GR, Drake RE, McHugo GJ. Strategies for improving fidelity in the National evidence-based practices project. Res Soc Work Pract 2009;19:569-81.

84 Brownson RC, Colditz GA, Proctor EK. Dissemination and implementation research in health: translation science to practice. New York, NY: Oxford University Press, 2018.

85 Proctor EK, Landsverk J, Aarons G, et al. Implementation research in mental health services: an emerging science with conceptual, methodological, and training challenges. Adm Policy Ment Health 2009;36:24-34.

86 Barac R, Kimber M, Johnson S, et al. The effectiveness of consultation for clinicians learning to deliver motivational interviewing with fidelity. J Evid Inf Soc Work 2018;15:510-33.

87 Herschell AD, Kolko DJ, Baumann BL, et al. The role of therapist training in the implementation of psychosocial treatments: a review and critique with recommendations. Clin Psychol Rev 2010;30:448-66.

88 Beidas RS, Kendall PC. Training therapists in evidence-based practice: a critical review of studies from a systems-contextual perspective. Clin Psychol 2010;17:1-30.

89 Creswell JW, Plano Clark VL. Desiging and conducting mixed methods research. 3rd edn. Los Angeles, CA: SAGE Publications, 2017.

90 Verma JP. Repeated measures design for empirical researchers. Hoboken, NJ: Wiley, 2016.

91 Sandelowski M. Focus on research methods: whatever happened to qualitative description. Res Nurs Health 2000;23:334-40.

92 Sandelowski M. What's in a name? Qualitative description revisited. Res Nurs Health 2010;33:77-84.

93 Fetters MD, Curry LA, Creswell JW. Achieving integration in mixed methods designs-principles and practices. Health Serv Res 2013;48:2134-56.

94 Zhang W, Creswell J. The use of "mixing" procedure of mixed methods in health services research. Med Care 2013;51:e51-7.

95 Statistics Canada. Hamilton City (CSD). Focus on geography series, 2016 census. Ottawa, Ontario: Statistics Canada, 2017.

96 Lancaster GA, Dodd S, Williamson PR. Design and analysis of pilot studies: recommendations for good practice. J Eval Clin Pract 2004:10:307-12.

97 Whitehead AL, Julious SA, Cooper CL, et al. Estimating the sample size for a pilot randomised trial to minimise the overall trial sample size for the external pilot and main trial for a continuous outcome variable. Stat Methods Med Res 2016;25:1057-73.

98 Billingham SAM, Whitehead AL, Julious SA. An audit of sample sizes for pilot and feasibility trials being undertaken in the United Kingdom registered in the United Kingdom clinical research network database. BMC Med Res Methodol 2013;13:104.

99 DeLong Goldman G, Goldman GD. Initial validation of a brief individual readiness for change scale (BIRCS) for use with addiction program staff practitioners. J Soc Work Pract Addict 2009:9:184-203.

100 Connor PD, Nouer SS, Mackey STN, et al. Psychometric properties of an intimate partner violence tool for health care students. $J$ Interpers Violence 2011:26:1012-35.

101 Short LM, Alpert E, Harris JM, et al. A tool for measuring physician readiness to manage intimate partner violence. Am J Prev Med 2006;30:173-80

102 Riggs ML, Warka J, Babasa B, et al. Development and validation of self-efficacy and outcome expectancy scales for job-related applications. Educ Psychol Meas 1994;54:793-802.

103 Merikangas K, Stringaris A. The CoRonavlruS health Impact Survey (CRISIS) V1 - Adult self-report baseline form onine: National Institute of Mental Health Intramural Research Program, 2020. Available: https://www.phenxtoolkit.org/toolkit_content/PDF/ CRISIS_Baseline_Adult.pdf [Accessed Jun 2020].

104 Maslach C, Jackson SE. The measurement of experienced burnout. J Organ Behav 1981;2:99-113.

105 Bride BE, Robinson MM, Yegidis B, et al. Development and validation of the secondary traumatic stress scale. Res Soc Work Pract 2004;14:27-35.
106 Beckstead JW. Isolating and examining sources of suppression and multicollinearity in multiple linear regression. Multivariate Behav Res 2012;47:224-46.

107 Cain MK, Zhang Z, Yuan K-H. Univariate and multivariate skewness and kurtosis for measuring nonnormality: prevalence, influence and estimation. Behav Res Methods 2017;49:1716-35.

108 Sandelowski M. Whatever happened to qualitative description? Res Nurs Health 2000;23:334-40.

109 Morse JM. Determining sample size. Qual Health Res 2000;10:3-5.

110 Cleary M, Horsfall J, Hayter M. Data collection and sampling in qualitative research: does size matter? J Adv Nurs 2014;70:473-5.

111 Palinkas LA, Horwitz SM, Green CA, et al. Purposeful sampling for qualitative data collection and analysis in mixed method implementation research. Adm Policy Ment Health 2015;42:533-44.

112 Patton MQ. Qualitative research and evaluation methods. 4th edn. Thousand Oaks, CA: SAGE Publications, 2015.

113 Rubin HJ, Rubin IS. Qualitative interviewing: the art of hearing data. Los Angeles, CA: SAGE, 2012

114 Thorne S. Interpretive description: qualitative research for applied practice. 2nd edn. New York, NY: Routledge, 2016.

115 Vaismoradi M, Turunen H, Bondas T. Content analysis and thematic analysis: implications for conducting a qualitative descriptive study. Nurs Health Sci 2013:15:398-405.

116 Crowe M, Inder M, Porter R. Conducting qualitative research in mental health: thematic and content analyses. Aust N Z J Psychiatry 2015;49:616-23.

117 Braun V, Clarke V. One size fits all? what counts as quality practice in (reflexive) thematic analysis? Qual Res Psychol 2020;2:1-25.

118 Birks M, Chapman Y, Francis K. Memoing in qualitative research: probing data and processes. $J$ Res Nurs 2008;13:68-75.

119 MacQueen KM, McLellan E, Kay K, et al. Codebook development for team-based qualitative analysis. CAM J 1998;10:31-6.

120 O'Cathain A, Murphy E, Nicholl J. The quality of mixed methods studies in health services research. J Health Serv Res Policy 2008;13:92-8

121 Guetterman TC, Fetters MD, Creswell JW. Integrating quantitative and qualitative results in health science mixed methods research through joint displays. Ann Fam Med 2015;13:554-61.

122 Morse JM. Critical analysis of strategies for determining rigor in qualitative inquiry. Qual Health Res 2015;25:1212-22.

123 Younas A, Pedersen M, Durante A. Characteristics of joint displays illustrating data integration in mixed-methods nursing studies. J Adv Nurs 2020;76:676-86.

124 Woodgate RL, Zurba M, Tennent P. Advancing patient engagement: youth and family participation in health research communities of practice. Res Involv Engagem 2018;4:9.

125 Davidson J, Wiens S, Anderson K. Creating a provincial family council to engage youth and families in child \& youth mental health systems. J Can Acad Child Adolesc Psychiatry 2010;19:169-75.

126 Richards T, Scowcroft H, BMJ's international patient and public advisory panel. Patient and public involvement in covid-19 policy making. BMJ 2020;370:m2575.

127 Ratneswaren A. The I in COVID: the importance of community and patient involvement in COVID-19 research. Clin Med 2020;20:e120-2.

128 O'Connor DB, Aggleton JP, Chakrabarti B, et al. Research priorities for the COVID-19 pandemic and beyond: a call to action for psychological science. Br J Psychol 2020;111:603-29.

129 Craig P, Dieppe P, Macintyre S, et al. Developing and evaluating complex interventions: the new medical Research Council guidance. BMJ 2008;337:a1655.

130 Eldridge SM, Lancaster GA, Campbell MJ, et al. Defining feasibility and pilot studies in preparation for randomised controlled trials: development of a conceptual framework. PLOS One 2016;11:e0150205.

131 Council MR. Developing and evaluating complex interventions. 39. 3rd edn. Online: Medical Research Council, 2019.

132 Thabane L, Ma J, Chu R, et al. A tutorial on pilot studies: the what, why and how. BMC Med Res Methodol 2010;10:1

133 Anderson L, Krathwohl DA. Taxonomy for learning, teaching, and assessing: a revision of bloom's taxonomy of educational objectives. New York, NY: Longman, 2001.

134 Bloom BS, Engelhart MD, Furst EJ. Taxonomy of educational objectives: the classification of educational goals. New York, NY: David McKay Company, 1956. 